deception. I believe the scientific method as it exists now is all we need as a community. Indeed, given the current power of the media, the quantity of academic fraud may well decrease, as potential fraudsters witness in full colour the disintegration of their dishonest colleagues.

Phil Bentley

Hahn-Meitner Institut, Glienicker Strasse 100, 14109 Berlin, Germany

\section{Pressure also leads to worthless publications}

SIR - Your Editorial "Ethics and fraud" (Nature 439, 117-118; 2006) does not address the problem of 'publish or perish'

Researchers are increasingly put under pressure to publish papers to further their career and access resources. But the fact that there are millions of pages published every month, only a few percent of which are worth reading, seems as much a fraud as the Hwang case. Are you wasting your time any more reading something fraudulent than reading something worthless? Neither helps the student or researcher wanting to do something concrete. It seems we have to read ten papers to get the one that really gives us something. The information is fragmented distributed across hundreds of publications, around the world, many of them inaccessible.

I suggest slowing down the paperpublishing machine by limiting the number of journals that publish original research, asking more peer-reviewers to read preprints and opening up preprint manuscripts for public discussion.

Lindomar B.de Carvalho

Intemational Centerfor Condensed Matter

Physics, Universidade de Brasília, Campus Darcy

Ribeiro, Caixa Postal 04513, Brasilia, DF - Brazil

\section{It's difficult to publish contradictory findings}

SIR - Your recent Editorial (Nature 439, $117-118$; 2006) bemoans the recurring subject of ethics and fraud in scientific research. I contend that many journals contribute to the prevalence of bad science, because, when the fundamental observation that led to the original publication cannot be reproduced, it is nearly impossible to publish a paper documenting this. Hence, controversies persist in the literature over many years, simply because the corrected story either is never published, or is not published as prominently as the initial paper.

True, there is an extensive specialist literature where ambiguous or conflicting results can be addressed in detail, but the readership is limited. Some journals, such as Nature, have mechanisms for publishing technical comments on published research (Brief Communications Arising: online only; see www.nature.com/nature/authors/gta/ briefcomms.html \#a2), but these are few in number and must adhere to strict criteria.

Reviewers of contradictory results often ask that the authors explain how the original authors could have obtained their results. To quote a recent rejection letter, "an adequate explanation for the apparent contradictory findings is not provided". Certainly, speculative explanations can be offered for some kinds of experimental differences. But it is never possible to prove how another lab obtained data that cannot be reproduced. One can only be certain of one's own data. This demand for explanation creates serious problems in the case of scientific fraud. In a minor case, the original authors may have fudged one small set of data to 'prove' their theory. In a more serious case, fundamental observations cannot be reproduced. Whether this irreproducibility is due to outright fraud, scientific incompetence or some combination cannot be determined by the authors who try to reproduce the result and fail.

Another often-made request of reviewers is that the original experiments be reproduced exactly. This sounds reasonable but, in fact, can become an absurd burden. Even if the methods section were complete and accurate, one can never say with certainty that one has reproduced the experimental conditions precisely. Instead, the appropriate approach is to design experiments to test the conclusions of the original paper. If these condusions are disproved, then the details of how they were arrived at are not relevant.

Of course, a contradictory paper should be held to a higher standard than was the paper it refutes. But all journals must endeavour to correct errors, or those who perpetrate scientific misconduct (not necessarily outright fraud) will be rewarded, and those who try to correct wrong hypotheses in the proper hegelian manner - thesis, antithesis, synthesis - will be punished.

Thomas E. DeCoursey

Molecular Biophysics and Physiology, Rush

University Medical Center, 1750 West Harrison

Street, Chicago, Illinois 60612-3824, USA

\section{Data audit would reduce unethical behaviour}

SIR — I agree with the point made in your Special Report "Should journals police scientific fraud?" (Nature 439, 520-521; 2006) that editorial offices are not the proper place to monitor fraud. This is why, 19 years ago, my colleague Zoltan Aannau and I proposed data audit (Nature 327, 550; 1987).

Research subject to data audit could include studies presenting possible risks to public health, or those questioned by a whistleblower or by peer review. Others could be subject to random audits. Up to $1 \%$ of all studies could be audited every three to five years, at less than $1 \%$ of the cost of the original study (Accountability Res. 1,77-83, 1989). Auditing could be done by an independent body that would certify the validity of published results. Sponsoring institutions could choose to publish a transparent analysis of selected papers on the web.

Although these processes might not eliminate all fraud or misconduct, they could substantially reduce such unethical practices. Adil E. Shamoo

Accountability in Research, University of Maryland School of Medicine, 108 North Greene Street, Baltimore, Maryland 21201, USA

\section{Discourse among referees and editors would help}

SIR - In the discussion on enhancing peer review, following publication of the controversial human-cloning papers in Science ("Ethics and fraud" Nature 439, 117-118; 2006), I would like to highlight one of the limitations of this process. Last year, I was asked to review a manuscript for a highimpact journal. Although I duly reviewed the paper - before the deadline and after extensive reading and research - I have yet to receive information on the paper's status.

I see three possible scenarios regarding the paper's fate: either it has been accepted or it has been rejected or the authors have been advised to revise it. In the first and second cases, a referee likes to know how an editor made their decision in light of, or in spite of, any objections raised. In the third case, each referee likes to know what comments or recommendations other referees and the editor have made, as well as details of the authors' rebuttal. Obviously each referee is an expert in his or her field, but not necessarily in the other sub-fields relevant to a particular manuscript. Sharing the referees' comments is essential to the learning (and in some cases validation/checking) process. It might also help clarify differences of opinion between referees of the same expertise. I believe discourse among the referees and editor would enrich the quality of reviewing and might prevent scandals such as the human stem-cell line cloning debacle.

\section{Debomoy K. Lahiri}

Institute of Psychiatric Research, Indiana University School of Medicine, 791 Union Drive, Indianapolis, Indiana 46202, USA

Nature editors aim to inform all peer reviewers when a final decision about publication of a manus cript is made, and to send reviewers each others ${ }^{t}$ reports on the manuscript, together with a letter of thanks - Editor, Nature. 